\title{
Could LUTS be Early Symptoms of COVID-19
}

\author{
Yeliz Kaya $^{1}$, Coskun Kaya ${ }^{2}$, Tugba Kartal ${ }^{3}$, Tugba Tahta ${ }^{3}$, and Yavuz Tokgöz ${ }^{3}$ \\ 1, Eskişehir Osmangazi University Faculty of Health Sciences, \\ ${ }^{2}$ Eskisehir City Hospital, Department of Urology \\ ${ }^{3}$ Affiliation not available
}

October 29, 2020

\begin{abstract}
Aim: To show if lower urinary tract symptoms (LUTS) could be symptoms of COVID-19 with validated questionnaires. Methods: The 96 COVID-19 patients who were hospitalized at a tertiary center were collected retrospectively. After the exclusion criteria, 46 patients were consisted as the study population. The male and female patients then fill formed the International Prostate Symptom Score and Urinary Symptom Profile respectively. All patients responded to these questions for the three period. Results: 27 female $(58.6 \%)$ and 19 male $(41.4 \%)$ COVID-19 patients answered the questions In the male patients, while there were no statistically significant differences in the total IPSS, the voiding IPSS score, and quality of life between the three periods $(\mathrm{p}=0.148 ; \mathrm{p}=0.933, \mathrm{p}=0.079$, respectively), the storage IPSS scores had a significant difference between the three periods $(\mathrm{p}=0.05)$. In the female patients, low stream scores, were similar between the three periods ( $\mathrm{p}=0.368)$. The scores of stress incontinence and an overactive bladder had a significant difference between the three periods ( $\mathrm{p}=0.05$ and $\mathrm{p}=0.05$ ). Conclusion: LUTS, especially storage symptoms, might be one of the initial symptoms of COVID-19 and the clinicians should evaluate LUTS with other known symptoms of the virus when a patient is suspected of having COVID-19.
\end{abstract}

\section{Could LUTS be Early Symptoms of COVID-19}

\section{Introduction}

The coronavirus 2019 (COVID-19) has been spreading rapidly from person to person and causing widespread disease over the world since the end of 2019. The spectrum of COVID-19 virus infection ranges from asymptomatic cases to fatal pneumonia. At the beginning of the pandemic, it was said that the most illnesses due to this virus could be self-limited, with an abrupt onset of fever and respiratory symptoms. With the increase of cases all over the world due to the high transmission rate, more symptoms such as fatigue, myalgia, diarrhea, loss of taste and smell have been described as the typical symptoms of COVID-19, and the high mortality rate has been shown among cases with co-morbid diseases.

The signs, symptoms, or laboratory findings of the effects of this illness on the urinary tract system have not yet been fully described in the literature (5-2). Firstly, Mumm et al found that urinary frequency might be a symptom of COVID-19 (5), then Luciani et al reported three cases of gross hematuria (6). While Sun et al firstly isolated the virus from the urine of a COVID-19 patient (8), Liu et al found that the positive rates of glucosuria and proteinuria may have a role on the differentiation of the severity of COVID-19 (1). According to our knowledge, there have been no reports that COVID-19 patients have been evaluated with a standardized questionnaire about their urinary tract system. In this study, we aimed to show if lower urinary tract symptoms (LUTS) could be symptoms of COVID-19 with validated questionnaires.

\section{Material-Methods}

After ethical committee approval and permission being granted by the Republic of Turkey Ministry of Health, the data of COVID-19 patients who were hospitalized between 15 May and 15 June 2020 at a tertiary center 
were collected retrospectively. The patients who were $<18$ years old, had any type of chronic medical illness, or any type of urinary cancers or history of urological operations were excluded from the study. The remaining patients were contacted and asked if they wanted to participate in the study. All of the patients agreed to participate and complete the questionnaires.

All patients answered socio-demographic form questions. Then the Male patients then replied to the questions of the International Prostate Symptom Score (IPSS), and female patients responded to the questions of the Urinary Symptom Profile (USP). Both male and female patients responded to these questions three times, based on their condition pre-COVID-19, during hospitalization, and post-hospitalized time. LUTS can be evaluated with a total IPSS score, and with this score system voiding and storage symptoms can be detected separately (10-19). USP, which was designed by Haab et al (11-8), and translated in Turkish by Bilge and Beji(11), has been used for both men and women who have stress incontinence, an overactive bladder, and/or obstructive symptoms.

The SPSS 21.0 program was used in the statistical analysis of the data. The variables were expressed as mean \pm standard deviation $(\mathrm{X} \pm \mathrm{SD})$, and the percent (\%) value was calculated for variables determined by the count. The "p" significance value was taken as 0.05 in all the statistical analyses.

\section{Results}

The 96 COVID-19 patients who were hospitalized between 15 May and 15 June 2020 at a tertiary center were collected retrospectively. After the exclusion criteria, 46 patients were consisted as the study population and all of the patients wanted to participate in the study. 27 female (58.6\%) and 19 male (41.4 \%) COVID-19 patients answered the questions of socio-demographic forms and the IPSS or UPS after $17.2 \pm 3.5$ days after being discharged from hospital. The socio-demographic data are shown in Table 1. The mean age of female and male patients was $32.3 \pm 8.9$ and $38.9 \pm 13$ years old, respectively.

In the male patients, while there were no statistically significant differences in the total IPSS, the voiding IPSS score, and quality of life between the three periods $(\mathrm{p}=0.148 ; \mathrm{p}=0.933, \mathrm{p}=0.079$, respectively $)$, the storage IPSS scores had a significant difference between the three periods $(\mathrm{p}=0.05$ (Table 2$)$.

In the female patients, low stream scores, which reflect obstructive symptoms, were similar between the three periods $(\mathrm{p}=0.368)$. The scores of stress incontinence and an overactive bladder had a significant difference between the three periods $(\mathrm{p}=0.05$ and $\mathrm{p}=0.05)$. (Table 3 ).

\section{Discussion}

Viral infections of the lower urinary tract are specially detected in immuno-compromised patients and are the major cause of hemorrhagic cystitis in the solid organ and stem cell transplant recipients $(9-1,2,3)$. To define viral cystitis, the viral pathogen should be evaluated from a urine sample and the patient must have hematuria, abdominal pain, urgency, frequency, pyuria and/or hematospermia (9). To date, COVID-19 was only be isolated from urine samples by Sun et al (8). Then Lie et al found that while urine occult blood, proteinuria, and the urine potential of hydrogen were higher in COVID-19 patients than in healthy controls, the urine specific gravity value was lower in patients than in healthy controls (1). In addition, they reported that the positive rates of glucosuria and proteinuria in the severe and critical groups were higher than those in the moderate group, as a result, they also suggested that urine findings could be useful for the evaluation of the illness (1).

Mumm et al suspected that if the patients had any urinary symptoms after they had treated a patient with COVID-19 presented as urosepsis (5). Then they evaluated 57 COVID-19 patients retrospectively and found that seven male patients had a urinary frequency (5). After this study's findings, Luciani et al reported three cases of COVID-19 who had gross hematuria (6). They recommended that clinicians should be aware that COVID-19 patients, especially those who had a history of urinary tract disease, could apply to the hospital with urinary tract symptoms (6).

In this study we evaluated COVID-19 patients for LUTS with validated instruments retrospectively for the 
first time. We excluded all medical and surgical conditions that might affect urinary tract symptoms and cause LUTS from the study. We found that the male patients did not have significant voiding symptoms during the illness or after the treatment, and these symptoms did not affect their quality of life. However, the storage symptoms were seen before the early time of illness and during COVID 19. With the discharge from hospital, these symptoms had disappeared. It could be explained that the storage symptoms might have occurred after the patient had been infected by the virus, so the storage symptoms may be one of the first symptoms of COVID-19 along with a fever or cough. In the female patients it could be said that the obstructive symptoms were similar before, during and after the illness. As with the male patients, the female patients had overactive bladder symptoms at the start of the illness and during hospitalized time, however these symptoms were cured at the time of resting at the home. When the medical reports of the patients were examined, any intravenous fluid supply or oral hydration therapy which could cause the urinary frequency, were not given as an medical order to any patients. The other possible reason of storage symptoms were the psychogenic LUTS or overactive bladder described by Sakakibara et al (13). It was found that the patients under the depressive condition could complain about the voiding symptoms, so infected with COVID-19, hospitalized and the fear of death could cause depressive moods to all patients. Also, we found that stress incontinence was higher during the active infection period rather than before and after the illness for the first time in the literature. This result could be explained that the cough is one of the main symptoms of COVID-19, so the increased cough could be expected to cause this incontinence. With the recovery from COVID-19, the cough would be less and so the stress incontinence would be detected less as a result.

The retrospective design with a small number of participants and the time of questionnaire completion are the major limitations of the study. Another limitation was that there were no urine biochemical results, voiding diary datas or uroflowmetry of the patients because the clinicians were not aware of the importance of urine results in the early days of the pandemic. The last limitation was there was no control group to compare the incidence of the symptoms.

In conclusion, we have tried to show the urinary symptoms of COVID-19 patients with validated tools for the first time in the literature. According to our results, LUTS, especially storage symptoms, might be one of the early symptoms of COVID-19 and the clinicians should evaluate LUTS with other known symptoms of the virus when a patient is suspected of having COVID-19.

\section{Author Contribution:}

YT contributed to data collection and analysis, manuscript writing, and revision. YK contributed to study design, manuscript writing, and revision. TK contributed to literature review, manuscript writing, and revision. TT contributed to data collection and analysis. CK contributed to study design, data analysis, and literature review.

\section{ORCID iDs}

Yeliz Kaya https://orcid.org/0000-0003-4277-3960

Coşkun Kaya https://orcid.org/0000-0002-7445-2304

Tuğba Kartal https://orcid.org/ 0000-0002-4329-0963

Tugba Tahta https://orcid.org/ 0000-0003-0190-977X

V.Yavuz Tokgöz https://orcid.org/ 0000-0002-4113-385X

\section{References:}

1. Wang D, Hu B, Hu C, et al. Clinical characteristics of 138 hospitalized patients with 2019 novel coronavirusinfected pneumonia in Wuhan, China. JAMA 2020;323:1061-9.

2. Mumm J-N, et al. Urinary Frequency as a Possibly Overlooked Symptom in COVID-19 Patients: Does SARS-CoV-2 Cause Viral Cystitis?. Eur Urol (2020), https://doi.org/10.1016/j.eururo.2020.05.013. 
3. Luciani LG, et al. Re: Jan-Niclas Mumm, Andreas Osterman, Michael Ruzicka, et al. Urinary Frequency as a Possible Overlooked Symptom in COVID-19 Patients: Does SARS-CoV-2 Cause Viral Cystitis? Eur Urol. In press. https://doi.org/10.1016/j.eururo.2020.05.013. Eur Urol (2020), https://doi.org/10.1016/j.eururo.2020.06.006.

4. Sun J, Zhua A, Li H, Zheng K, Zhuang Z, Chen Z, Shi Y, Zhang Z, Chen S, Liu X, Dai J, Li X, Huang S, Huang X, Luo L, Wen L, Zhuo J, Li Y, Wang Y, Zhang L, Zhang Y, Li F, Feng L, Chen X, Zhong N, Yang Z, Huang J, Zhao J and Li Y. Isolation of infectious SARS-CoV-2 from urine of a COVID-19 patient. Emerging Microbes \& Infections 2020, VOL. 9 https://doi.org/10.1080/22221751.2020.1760144.

5. Liu et al.: The value of urine biochemical parameters in the prediction of the severity of COVID-19. Clin Chem Lab Med 2020; 58(7): 1121-1124.

6. Barry, M.J.; Fowler, F.J.; O’Leary, M.P.; Bruskewitz, R.C.; Holtgrewe, H.L.; Mebust, W.K.; Cockett, A.T. Measurement Committee of the American Urological Association. The American Urological Association symptom index for benign prostatic hyperplasia. J. Urol. 1992, 148, 1549-1557.

7. Haab F, Richard F, Amarenco G, Coloby P, Arnould B, Benmedjahed K, et al. Comprehensive evaluation of bladder and urethral dysfunction symptoms: development and psychometric validation of the urinary symptom profile (USP) questionnaire. Urology. 2008;71(4): 646-56.

8. Bilge Ç, Kızılkaya Beji N. Üriner Semptom Profili'nin Türkçe'ye Uyarlanması: Geçerlik ve Güvenirlik Çalışması. Düzce Üniversitesi Sağlık Bilimleri Enstitüsü Dergisi, 2016; 6(3):154-160.

9. Yusuf U, Hale GA, Carr J, et al.: Cidofovir for the treatment of adenoviral infection in pediatric hematopoietic stem cell transplant patients. Transplantation 2006, 81:1398-1404.

10. Bonetti et al.: Urinalysis predicting COVID-19 severity. Clin Chem Lab Med 2020, https://doi.org/10.1515/cclm-2020-0576.

11. Allen R.J. et al.: Uncomplicated cystitis in an adult male following influenza B virus infection. Am J Case Rep, 2017; 18: 190-193.

12. Paduch DA. Viral lower urinary tract infections. Curr Urol Rep. 2007;8:324-35.

13. Sakakibara R, Ito T, Yamamoto T, Uchiyama T, Yamanishi T, Kishi M, Tsuyusaki Y, Tateno F, Katsuragawa S, Kuroki N. Depression, anxiety and the bladder. Low Urin Tract Symptoms. 2013; 5: 109-120.

Table 1. Socio-demographic data of the participants

Table 2.Comparison of the mean scores of the IPSS scale pre-COVID-19, during hospitalization, and posthospitalized time'.

Table 3.Comparison of the mean scores of the USP scale pre-COVID-19, during hospitalization, and posthospitalized time'.

Hosted file

tables.pdf available at https://authorea.com/users/348108/articles/489679-could-luts-beearly-symptoms-of-covid-19 